Achintya D. Singh, MBBS, MD

Resident, Department of Internal Medicine,

Cleveland Clinic, Cleveland, $\mathrm{OH}$
Agrima Mian, MD

Resident, Department of Internal Medicine,

Cleveland Clinic, Cleveland, $\mathrm{OH}$
James K. Stoller, MD, MS

Chairman, Education Institute; Staff, Department

of Critical Care Medicine, Respiratory Institute,

Cleveland Clinic, Cleveland, OH; Professor,

Cleveland Clinic Lerner College of Medicine of

Case Western Reserve University, Cleveland, $\mathrm{OH}$

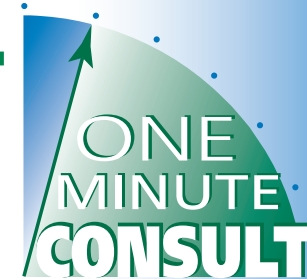

BRIEF ANSWERS

TO SPECIFIC

CLINICAL

QUESTIONS

\title{
Is it safe to start steroids at home for a COPD exacerbation after virtual assessment in the COVID-19 era?
}

\begin{abstract}
A:
A 63-YEAR-OLD MAN with chronic obstructive pulmonary disease (COPD), using an albuterol inhaler as needed, called our nurse triage line in October 2020 because his chronic cough had worsened over the past 7 days. In this time, he occasionally had wheezing when breathing, but he noted no increase in shortness of breath. The nurse advised him to be tested for coronavirus and scheduled a follow-up virtual visit for 3 days later.
\end{abstract}

By then, his symptoms were worse. The cough was productive, associated with occasional mucoid expectoration, and now interfered with sleep. He said he still occasionally had wheezing on respiration but did not have worsened shortness of breath, fever, sore throat, myalgias, or diarrhea. Because he lacked transportation and social support, he could not undergo the recommended coronavirus test. He had never undergone pulmonary function testing at our institution, and had never been hospitalized for similar concerns.

On virtual examination, he appeared comfortable. His respiratory rate was 24 breaths per minute, and he did not appear to be using accessory muscles of respiration. No wheezing could be heard.

Based on the impression that the patient was experiencing an acute exacerbation of COPD, ${ }^{1}$ should he be prescribed a corticosteroid, and can this be done safely?

The answer to both questions is yes.

In acute exacerbations of COPD, systemic corticosteroids have been shown to accelerate improvement in airflow, delay the time to recurrence, and, in hospitalized patients, reduce the length of stay. ${ }^{2-4}$ A 5-day course of doi:10.3949/ccjm.88a.20194 prednisone $40 \mathrm{mg} /$ day has been shown to be noninferior to a longer (14-day) course and is generally well tolerated. ${ }^{4}$

The dilemma posed by our patient-new cough and phlegm in a patient with COPDposes a common challenge in the COVID-19 pandemic, as the differential diagnosis also includes COVID-19. ${ }^{5}$

Virtual visits are appropriate during the pandemic, given the risk a potentially infected individual poses to others. The use of virtual visits has expanded rapidly during the pandemic. Yet a virtual assessment of a patient with COPD who is suspected of having an acute exacerbation is limited in some ways.

\section{COPD VS COVID-19:}

DIAGNOSTIC CHALLENGE

The clinical features of acute exacerbation of COPD — worsened shortness of breath and cough-overlap with those of COVID-19, and this was the reason for recommending COVID-19 testing in our patient. Compounding this diagnostic dilemma, COPD is a risk factor for severe COVID-19 and adverse clinical outcomes of COVID-19. ${ }^{3}$ Managing acute exacerbations of COPD during this pandemic is further complicated by increased demands for healthcare, limited access to healthcare, and heightened reluctance of patients to go to the hospital.

Hospital admissions for acute exacerbations of COPD have declined recently, ${ }^{6}$ likely because patients don't want to go to the hospital, and hospitals are admitting only the sickest patients. Another reason may be that there are fewer COPD exacerbations due to less air pollution because people are working
Although virtual visits

have limitations,

they are valuable 
TABLE 1

\section{Virtual assessment of acute COPD exacerbation}

\begin{tabular}{ll} 
Assessment $^{\text {a }}$ & Interpretation \\
\hline Count the respiratory rate & $\begin{array}{l}\text { A rate }>30 \text { breaths/minute indicates } \\
\text { increased work of breathing }\end{array}$ \\
\hline
\end{tabular}

If possible, note increased Increased accessory muscle activity activity of accessory muscles indicates ongoing respiratory distress

Assess mentation and look for Changes in mentation and presence flapping tremors (asterixis) of asterixis suggest ongoing acute respiratory failure

a There is no clear guidance on the assessment of acute exacerbation of chronic obstructive pulmonary disease (COPD) through a virtual visit. This table is to help clinical assessment through virtual visits and is drawn from the Global Initiative for Chronic Obstructive Lung Disease recommendations for assessment of exacerbation of COPD for hospitalized patients.

Based on information in reference 7 .

The clinical

\section{features}

of acute

exacerbation

of COPD

overlap

with those

of COVID-19 from home and not traveling as much. Also, patients with chronic cough can be reflexively suspected of having COVID-19, and in-office visits are sometimes discouraged based on the infectious risk.

Together, these factors have made virtual visits a mainstay of managing patients with COPD during the pandemic.

\section{VIRTUAL ASSESSMENT OF ACUTE EXACERBATIONS OF COPD}

Virtual visits have provided a portal for healthcare access while mitigating infection risks. They can allow one to form a clinical impression and to decide whether the patient needs emergent, in-person care vs continued virtual management. On the other hand, virtual visits also limit the clinician's assessment, eg, confining the physical examination to observation and not allowing direct examination, laboratory work and, in some cases, pulse oximetry.

Though studies have examined the value of self-management strategies for COPD with on-line and telephonic backup, ${ }^{5}$ to our knowledge, no published report has specifically addressed best practices in virtual visit assessment of patients with COPD.

A careful history is important to elicit a history of exposure to individuals known to have SARS-CoV-2, and also to assess whether the current illness resembles prior exacerba- tions the patient may have experienced.

Visual inspection is critical and plays an even more important role during a virtual visit. Drawing from the Global Initiative for Chronic Obstructive Lung Disease 2020 guidelines for managing acute exacerbations of COPD, assessing the patient's respiratory rate, use of accessory muscles, mentation, and oxygenation and observing for asterixis are especially important during a virtual visit (Table 1). ${ }^{7}$ Establishing whether the patient has a normal respiratory rate $(<30$ breaths per minute), has obvious cyanosis, is using accessory muscles of respiration, has asterixis, and has normal mentation helps determine the urgency of care, and the normal findings in our patient are reassuring.

Close serial follow-up with frequent reassessments to gauge the trajectory of the patient's illness becomes more important when the initial assessment is limited, as in a virtual visit. ${ }^{8}$ Conversely, worrisome findings on initial assessment such as tachypnea, gross cyanosis, accessory muscle use, paradoxic inward motion of the abdomen on inspiration, asterixis, or confusion should prompt a recommendation to go to the nearest emergency room or call 911.

\section{TREATING ACUTE EXACERBATIONS OF COPD IN THE COVID-19 ERA}

We could not confidently exclude COVID-19 in this case. Because corticosteroids are indicated in acute exacerbations of COPD, the current case prompts 2 questions:

- Should corticosteroids be prescribed (eg, prednisone $40 \mathrm{mg}$ daily for 5 days, as was used in the Reduction in the Use of Corticosteroids in Exacerbated COPD [REDUCE] trial $\left.^{4}\right)$ ?

- Would corticosteroids adversely affect outcomes if the patient actually has COVID-19?

Regarding the latter question, the Randomized Evaluation of Covid-19 Therapy (RECOVERY) trial demonstrated that, in hospitalized patients with COVID-19 needing supplemental oxygen or mechanical ventilation, fewer patients died who received dexamethasone $6 \mathrm{mg}$ daily for up to 10 days compared with usual care alone. ${ }^{9}$ Neither ben- 
efit nor excess harm with dexamethasone was shown for patients with COVID-19 not needing supplemental oxygen and not on a ventilator, supporting the recommendation that inhaled corticosteroids not be withdrawn in COPD patients who contract COVID-19 and that systemic steroids, whether dexamethasone or other steroids in equivalent doses, can be used when indicated. ${ }^{5}$

Notably, prednisone $40 \mathrm{mg}$ is roughly equivalent to dexamethasone $6 \mathrm{mg}$ in glucocorticoid potency, though the duration of treatment for a COPD exacerbation (5 days) is less than that for severe COVID-19 disease (up to 10 days). ${ }^{10}$

\section{BACK TO THE PATIENT}

The patient was started on oral prednisone $40 \mathrm{mg}$ for 5 days for what was presumed to be an acute exacerbation of COPD. He was later able to get a polymerase chain reactionbased test for SARS-CoV-2, which was negative. On follow-up 1 week after the initial virtual visit, his symptoms had dramatically improved, and he reported being back to his usual state of health.

\section{VIRTUAL VISITS ARE VALUABLE}

In summary, clinically differentiating acute exacerbation of COPD from COVID-19 poses challenges that are exaggerated by some limitations of the virtual visit. But despite the limitations, taking a systematic approach to the history and maximizing visual assessment, as with this patient, can help the patient safely get through the acute illness. It is prudent to plan frequent short-term virtual reassessments to assess the course of the patient's illness, especially when diagnostic evaluation is limited.

Although the efficacy of virtual visits has not been established for patients with COPD in general nor for those experiencing an exacerbation that might resemble COVID-19, this experience supports the value of virtual visits, coupled with a careful history and clinical observation during the visit.

\section{DISCLOSURES}

Dr. Stoller has disclosed consulting for Dicerna Pharmaceuticals. All other authors report no relevant financial relationships which, in the context of their contributions, could be perceived as a potential conflict of interest.

\section{REFERENCES}

1. Anthonisen NR, Manfreda J, Warren CP, Hershfield ES, Harding GK, Nelson NA. Antibiotic therapy in exacerbations of chronic obstructive pulmonary disease. Ann Intern Med 1987; 106(2):196-204. doi:10.7326/0003-4819-106-2-196

2. Niewoehner DE, Erbland ML, Deupree RH, et al. Effect of systemic glucocorticoids on exacerbations of chronic obstructive pulmonary disease. Department of Veterans Affairs Cooperative Study Group. N Engl J Med 1999; 340(25):1941-1947. doi:10.1056/NEJM199906243402502

3. Albert RK, Connett J, Bailey WC, et al. Azithromycin for prevention of exacerbations of COPD. N Engl J Med 2011; 365(8):689-698. doi:10.1056/NEJMoa1104623

4. Leuppi JD, Schuetz P, Bingisser R, et al. Short-term vs conventional glucocorticoid therapy in acute exacerbations of chronic obstructive pulmonary disease: the REDUCE randomized clinical trial. JAMA 2013; 309(21):2223-2231. doi:10.1001/jama.2013.5023

5. Leung JM, Niikura M, Yang CWT, Sin DD. COVID-19 and COPD. Eur Respir J 2020; 56(2):2002108. doi:10.1183/13993003.02108-2020
6. Berghaus TM, Karschnia P, Haberl S, Schwaiblmair M. Disproportionate decline in admissions for exacerbated COPD during the COVID-19 pandemic. Respir Med 2020 Aug 14;106120. doi:10.1016/j.rmed.2020.106120

7. Global Initiative for Chronic Obstructive Lung Disease. GOLD COVID-19 guidance. Accessed March 4, 2021. https://goldcopd.org/ gold-covid-19-guidance/

8. Stoller JK, Bakow ED, Longworth D. Critical Diagnostic Thinking in Respiratory Care: A Case-Based Approach. 1st Edition. Philadelphia: WB Saunders; 2002.

9. RECOVERY Collaborative Group; Horby P, Lim WS, Emberson JR. Dexamethasone in hospitalized patients with Covid-19. N Engl J Med 2021; 384(8):693-704. doi:10.1056/NEJMoa2021436

10. National Institutes of Health. COVID-19 Treatment Guidelines. Corticosteroids. November 3, 2020. Accessed March 4, 2021. https:// www.covid19treatmentguidelines.nih.gov/immune-based-therapy/ immunomodulators/corticosteroids/

Address: Achintya D. Singh, MD, Internal Medicine Residence Program, NA10, Cleveland Clinic, 9500 Euclid Avenue, Cleveland, OH 44195; singha8@ccf.org 